\title{
Clinico-Pathological Study of Prognostic Factors in HER-2 Positive Patients with Breast Cancer
}

\author{
MOHAMED IBRAHIM ABO AL-SAAD IBRAHIM, M.Sc.*; HAMED RASHAD MOSALAM, M.D.**; \\ MOHAMED MAHMOUD MOHAMED AHMED, M.D.** and EL-SAYED A. ABD EL-MABOOD, M.D.** \\ The Department of Surgical Oncology, 6 th of October Hospital, Health Insurance* and The Department of General Surgery, \\ Benha University, Benha**, Egypt
}

\begin{abstract}
Background: Recurrence of disease is one of the major problems in patients with breast cancer during the first 2 years after diagnosis. Now, considering advanced laboratory techniques and complementary therapies, the rate of breast cancer recurrence has decreased.

Aim of Study: The rationale of this study is to discuss the clinico-pathological prognostic factors in HER2/neu positive breast cancer.

Patients and Methods: This current study was conducted on 50 patients diagnosed with breast cancer. Patients in this study were underwent either Modified radical mastectomy (MRM) or Breast conserving therapy (BCT) with axillary lymph nodes dissection. The follow-up period varied between 12 months to 24 months.

Results: No mortality related to surgery was reported. Outcome of surgery was flap necrosis in 2 patients (4\%), seroma in 3 patients $(6 \%)$ but infection only in one patient $(2 \%)$. Recurrence was observed in ten patients $(20 \%)$. Three patients $(6 \%)$ died during their follow-up due to distant metastasis. All recurrent patients having grade N3 $>9$ positive lymph nodes; $p$-value; 0.0001 .

Conclusion: Prognostic factors in HER-2 positive patients with breast cancer play important roles and it is considered an indicator of recurrence and the predictor of overall survival. The most significant prognostic is axillary lymph nodes involvement.
\end{abstract}

Key Words: Breast cancer-HER2 incidence - Prognostic factors-Outcomes.

\section{Introduction}

BREAST cancer is the most common cancer and the second most common cause of death from cancer in women. Because of the high frequency of the disease and the esthetic and symbolic value invested in the breast, breast cancer has always

Correspondence to: Dr. Mohamed Ibrahim Abo Al-Saad Ibrahim, The Department of Surgical Oncology, 6 th October Hospital, Health Insurance, Egypt been a source of severe distress to patients and their families. For the same reasons, breast cancer research has increased dramatically during the last 2 decades, resulting in extraordinary progress in our understanding of the disease and in new, more efficient and less toxic treatments. Furthermore, the diffusion of knowledge, the medical advancements, and the increased public awareness have led to earlier diagnosis at stages usually amenable to complete resection and potential cure of the disease [1].

Over the past few decades, breast cancer management has undergone significant changes characterized by less aggressive approaches to diagnosis and treatment. Mammogram and ultrasound or stereotactic biopsies have supplanted clinical diagnosis and surgical biopsy for the diagnosis; breastconserving surgery (BCS) and sentinel lymph node biopsy (SLNB) have successfully replaced the more aggressive radical mastectomy(RM) and axillary lymph node dissection (ALND) [2] .

Modern trials comparing different forms of loco-regional control for patients at the same stage of disease show that variations in local treatment do not result in differences in long-term survival, validating the first premise of these models regarding the inadequacy of local approaches to control the disease in the absence of systemic therapy. In addition, screening mammography results in early detection of breast cancer (average size $1.4 \mathrm{~cm}$ vs $2.2 \mathrm{~cm}$ for tumors clinically detected) and is associated with a $25 \%$ decrease in the mortality rate for breast cancer, thus lending credibility to the spectrum model. This model stresses the importance of both local and systemic treatment [3].

Lymph node status is a significant prognostic factor. Axillary lymph node involvement and the 
number of lymph nodes involved remain the most important prognostic factors for invasive breast cancer [4].

Hereditary breast cancers have been thought to represent a small proportion (5-10\%) of all breast cancers. However, based on new data derived from the comparison of identical and non identical twins, up to $27 \%$ of breast cancers may be attributed to inherited factors. The mutated genes BRCA $1 \& 2$ are responsible for approximately $30-40 \%$ of inherited breast cancers [5] .

Estrogens, by their proliferation-promoting effect on the breast epithelium later, increase the chance of DNA replication errors leading to carcinogenic mutations. Indeed, the common denominator to many of these risk factors is their effect on the level and duration of exposure to endogenous estrogenic stimulation [6].

The epidermal growth factor (EGF) receptor family plays a critical role in mammary tumor genesis. Other than the EGF receptor itself, 3 other members of this family have been described, including c-erb-B2 (HER2, HER2/neu), c-erb-B3, and c-erb-B4; the latter is called a kinase-dead receptor because it does not carry a kinase function on the cytoplasmic domain of the receptor, which is in contrast to the other members of the family [7].

The discovery of the role of HER 2 in breast cancer was one of the landmarks in breast cancer research in the last 2 decades. HER 2 is over expressed in $20-30 \%$ of breast cancers. Tumor cells over expressing HER2/neu may have up to 2 million copies of the receptor on their surface compared with 20,000-50,000 copies in normal breast epithelial cells. Because of this abundance of HER2/neu, many heterodimers contain HER2/neu, resulting in potent intracellular signaling and malignant growth [8].

Despite persistent controversy regarding certain aspects of its biology, prognostic value, and methods of evaluation, HER2 overexpression or amplification is generally accepted to be correlated with a high histologic grade, the absence of hormone receptor expression, aneuploidy, a high proliferation index, tumor size, and a poor clinical outcome. Its role as a predictor of response to chemotherapy and hormonal therapy (HT) is not clearly defined [9].

\section{Patients and Methods}

This current study was conducted on 50 patients diagnosed with breast cancer in the Department of
Surgery at Benha University and department of surgical oncology in 6 th October Hospital, Health Insurance Organization.

After local ethical committee of Benha University and 6 th October Insurance Hospitals approval and obtaining written fully informed patients consent, Patients with breast cancer were enrolled at these 2 clinical centers; From January 2015 till February 2019; So the enrollment period was 24 months and the patient follow-up period varied between 12 months to 24 months.

Patients included in this study were female patients fit for general anesthesia with Histopathologically proved breast cancer, Any T and Any N. But patients excluded from this study were male patients, patients with distant metastasis, patients unfit for general anesthesia; ASAIV and All deaths that occurred during this study due to non surgical cause i.e. pulmonary embolism, myocardial infarction, stroke, ... etc.

All patients in this study were underwent proper History taking, General and local clinical examination, Laboratory examination in the form of $\mathrm{CBC}$, Liver functions, kidney functions, RBS, PT and PC. Radiological examination in the form of Chest X-ray, Abdominal U/S, Bilateral breast mammography with complementary breast U/S, Bone scan. ECG for patients above 50 years and Pathological diagnosis by True cut or excisional biopsy.

\section{Operative procedure:}

Patients in this study were underwent either Modified radical mastectomy (MRM) or Breast conserving therapy (BCT) with axillary lymph nodes dissection. Anaesthesia was of general type.

\section{I- Modified radical mastectomy:}

A modified radical mastectomy removes all breast tissue, the nipple-areola complex, necessary skin, and the level I, II and III axillary lymph nodes. Upon positioning of the patient and applying betadine antiseptic solution; Skin incision was done. Then Skin flaps were developed with consistent thickness to avoid creation of devascularized subcutaneous tissues, which can contribute to wound seroma, skin necrosis, and flap retraction; using cautery or scalpel and extend to the boundaries of dissection for the modified radical mastectomy, which are (a) The anterior margin of the latissimus dorsi muscle laterally, (b) The midline of the sternum medially, (c) The subclavius muscle superiorly, and (d) The caudal extension of the breast, which is 3 to $4 \mathrm{~cm}$ inferior to the inframammary fold, till the rectus sheath; Once the skin 
flaps were developed, the breast parenchyma and pectoralis major fascia were elevated from the underlying pectoralis major muscle in a plane parallel with the muscle bundles as they course from their medial origin (ribs 2 to 6 ) to their lateral insertion on the humerus. Perforating vessels from the lateral thoracic or anterior intercostal arteries, which are end arteries, were individually secured. Elevation of the breast parenchyme and pectoralis major fascia was continued laterally until the lateral edge of the pectoralis major muscle and the underlying pectoralis minor muscle were exposed. Once elevation of the breast parenchyme and pectoralis major muscle fascia from the underlying pectoralis major muscle was completed, an incontinuity axillary lymph node dissection was performed. the pectoralis minor muscle was defined, and lymph nodes, which may lie between the pectoralis mus-

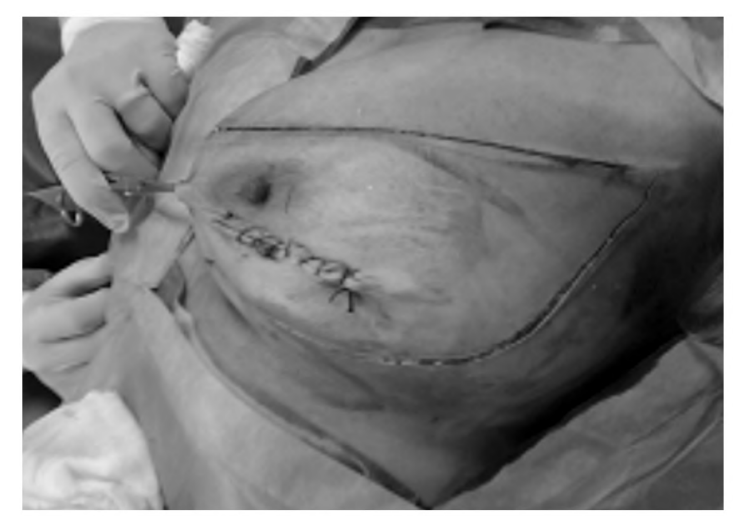

A- Skin incision "Oblique".

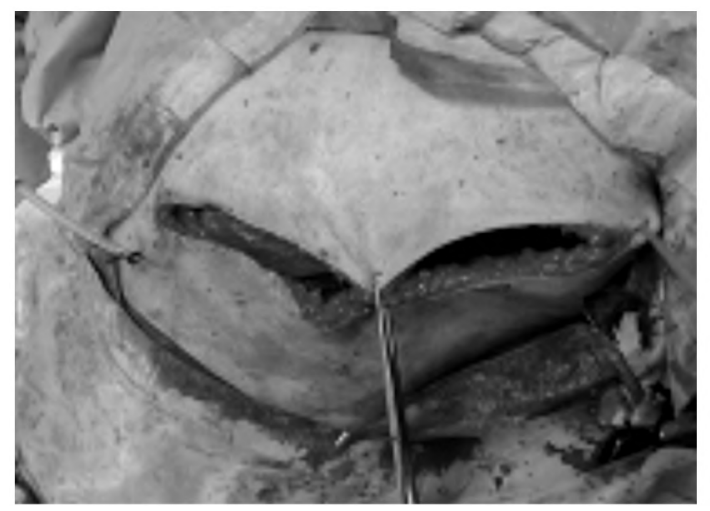

C- Closure of the skin. cles (Rotter nodes), were cleared. As the axillary lymph node dissection proceeded, the loose areolar tissue of the lateral axillary space is elevated with identification of the lateral extent of the axillary vein in its course anterior and caudal to the brachial plexus and axillary artery. (The axillary contents was removed in a medial to lateral direction). The investing layer of the axillary vein was dissected sharply, with allowing complete visualization of the anterior and ventral surfaces of the vein. Ligation and division of intervening venous tributaries is performed. Dissection continued till complete axillary clearance (level I,II,III) was done with preservation of nerve to serratus anterior \& nerve to latissmus dorsi muscle. After assuring hemostasis, Skin flaps were closed over medially placed drain. Fig. (1).

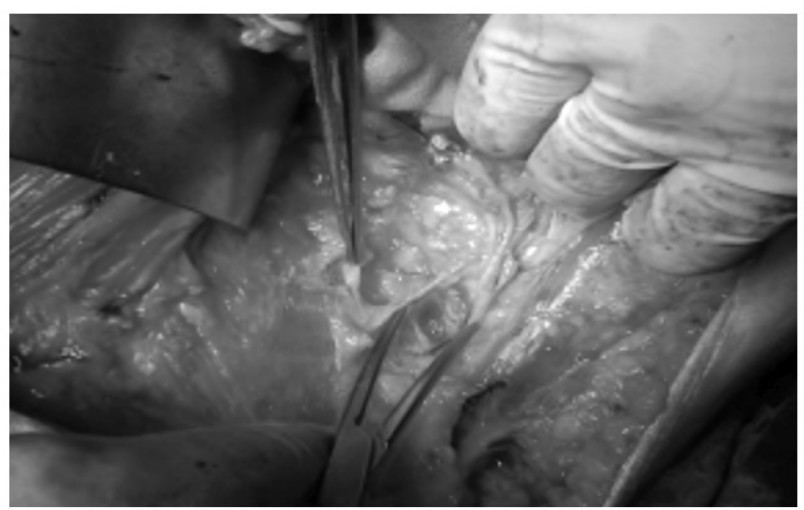

B- Preservation of nerve to latissmus dorsi \& nerve to serratus anterior muscle.

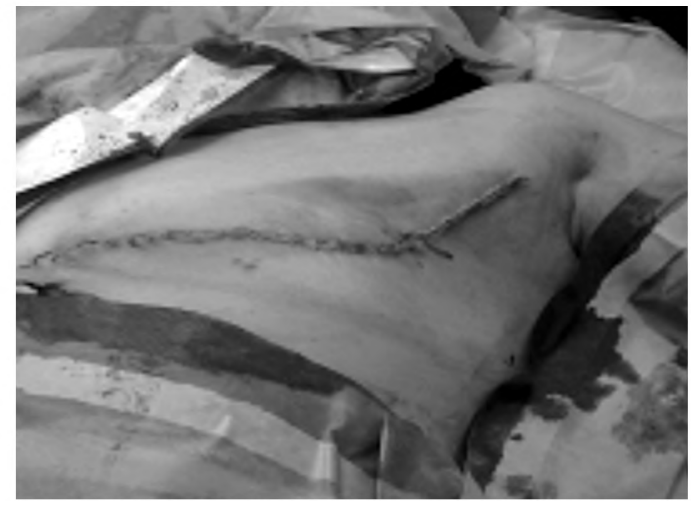

D- Skin closed over Sc drain.

Fig. (1A-D): Steps of modified radical mastectomy; case (1); Lt breast.

\section{II- Breast conserving therapy:}

Tumor control é acceptable appearance of the breast that included lumpectomy (safety margin $1 \mathrm{~cm}$ ) with axillary clearance up level III in addition to post-operative radiotherapy. This was done by two separate incision 1 st around the mass (its edges were marked for proper safety margins) and the other incision was done at the anterior axillary fold between latissmus dorsi and pectoralis major muscle.

\section{Outcome items:}

All specimens was sent for Histo-pathological study and Immuno-histochemistry for ER, PR and HER2 receptors. 
Postoperative outcome items included incidence of recurrence (local and distant), overall survival and complications; duration \& amounts of seroma, removal of the drain, hematomas, wound infection, skin loss ... etc.

\section{Statistical analysis:}

The collected data were tabulated and analyzed using SPSS version 16 soft ware (SpssInc, Chicago, ILL Company. Categorical data were presented as number and percentages using Fisher's exact test (FET) for their analysis. While quantitative data were expressed as mean \pm standard deviation and range. They were tested for normality using Shapiro-Wilks test, assuming normality at $p>0.05$. Student " $t$ " test was used to analyze normally distributed variables among 2 independent groups. While non parametric variables were analyzed using Man Whitney U test. Difference among 3 independent means was analyzed using ANOVA for parametric variables or Kruskal Wallis test (KW) for non parametric ones. The accepted level of significance in this work was stated at 0.05 ( $p<0.05$ was considered significant).

\section{Results}

No mortality related to surgery was reported; Age range was 29-84 years old with Mean \pm SD was 51.6 \pm 10.9 ; All patients were fit for general anesthesia depending on American Society of Anesthesiologists; ASAI and ASAII. Site of the tumor was common in UOQ; 43 patients $(86 \%)$. The range of tumor size was $(0.2-16.0 \mathrm{~cm})$ with Mean \pm SD; 5.8 \pm 3.5. Table (1), Fig. (2).

Table (1): Socio-demographic data of the studied patients.

\begin{tabular}{|c|c|c|}
\hline Variable & No. $(\mathrm{N}=50)$ & $(100 \%)$ \\
\hline \multicolumn{3}{|l|}{ Age (years): } \\
\hline Mean \pm SD (Range) & \multicolumn{2}{|c|}{$51.6 \pm 10.9(29-84)$} \\
\hline \multicolumn{3}{|l|}{ Site: } \\
\hline UOQ & 43 & 86.0 \\
\hline LOQ & 3 & 6.0 \\
\hline LIQ & 3 & 6.0 \\
\hline UIQ & 1 & 2.0 \\
\hline \multicolumn{3}{|l|}{ Size $(\mathrm{cm})$ : } \\
\hline Mean \pm SD (Range) & \multicolumn{2}{|c|}{$5.8 \pm 3.5(0.2-16.0)$} \\
\hline $\begin{array}{l}\text { UOQ = Upper Outer Quadrant. } \\
\text { LOQ = Lower Outer Quadrant. } \\
\text { LIQ = Lower Inner Quadrant. } \\
\text { UIQ = Upper Inner Quadrant. } \\
\text { - Data are presented as numbers } \\
\text { are in parenthesis. }\end{array}$ & nean \pm SD; pe & s \& ranges \\
\hline
\end{tabular}

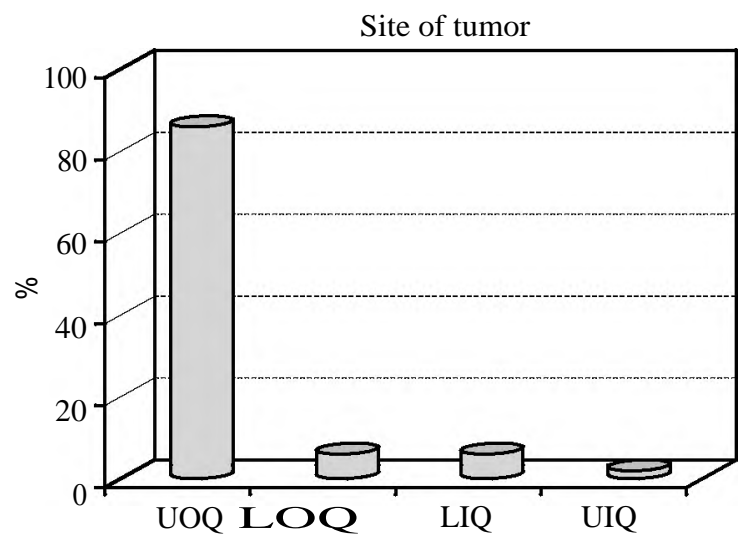

Fig. (2): Site of the tumor of the studied patients.

In tumor pathology; most of tumors were invasive in 47 patients (94\%); of Ductal carcinoma type in 41 patients (82\%). Table (2), Fig. (3).

Table (2): Histopathology and type of the tumor.

\begin{tabular}{lll}
\hline Variable & No. $(\mathrm{N}=50)$ & $(100 \%)$ \\
\hline $\begin{array}{l}\text { Histopathology: } \\
\quad \text { Insitu }\end{array}$ & 3 & \\
$\quad$ Invasive & 47 & 6.0 \\
Type: & & 94.0 \\
Ductal carcinoma & 41 & \\
Ductal carcinoma insitu & 3 & 82.0 \\
Lobular carcinoma & 4 & 6.0 \\
$\quad$ Mucinous carcinoma & 1 & 8.0 \\
Undifferentiated carcinoma & 1 & 2.0 \\
\end{tabular}

Data are presented as numbers \& percentages are in parenthesis.

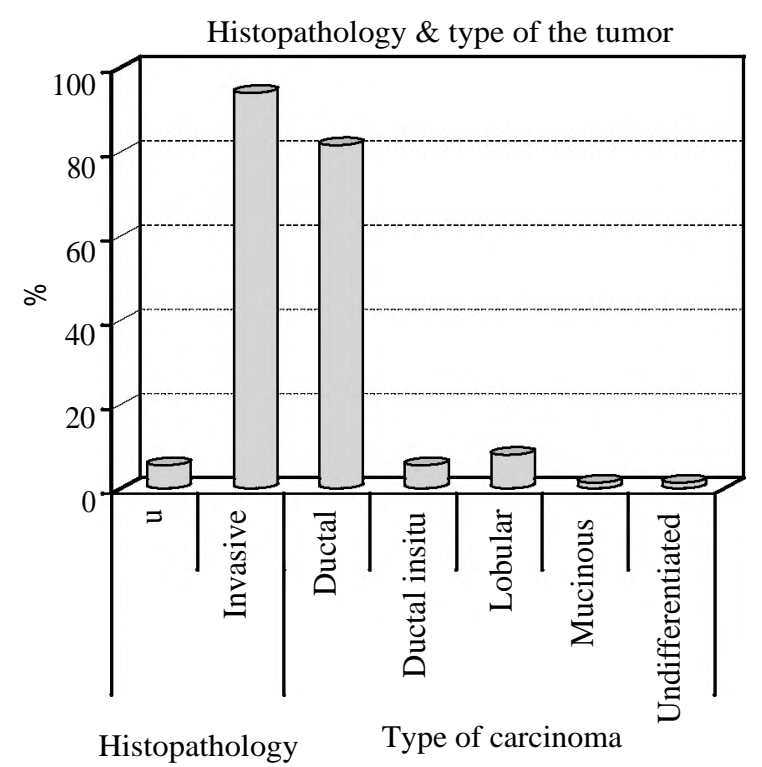

Fig. (3): Histopathology and type of the tumor.

As regard to lymph nodes and hormonal status; positive lymph nodes were equally distributed. But hormonal status; patients with positive ER \& PR receptors were more; $37 \& 32$ patients $(74.0 \% \&$ $64.0 \%$ ) respectively. Table (3), Fig. (4). 
Table (3): Distribution of lymph nodes and hormonal status.

\begin{tabular}{lcc}
\hline Variable & No. $(\mathrm{N}=50)$ & $(100 \%)$ \\
\hline LNs: & & \\
$\mathrm{N}_{0}=0$ LNs & 12 & 24.0 \\
$\mathrm{~N} 1=1-3 \mathrm{LNs}$ & 16 & 32.0 \\
$\mathrm{~N} 2=4-9$ LNs & 12 & 24.0 \\
$\mathrm{~N} 3>9$ LNs & 10 & 20.0 \\
ER receptors: & & \\
$\quad$ Negative & 13 & 26.0 \\
Positive & 37 & 74.0 \\
PR receptors: & & \\
$\quad$ Negative & 18 & 36.0 \\
Positive & 32 & 64.0 \\
\hline
\end{tabular}

LNs $=$ Lymp nodes. ER $=$ Estrogen. $\mathrm{PR}=$ Progesterone.

Data are presented as numbers \& percentages are in parenthesis.

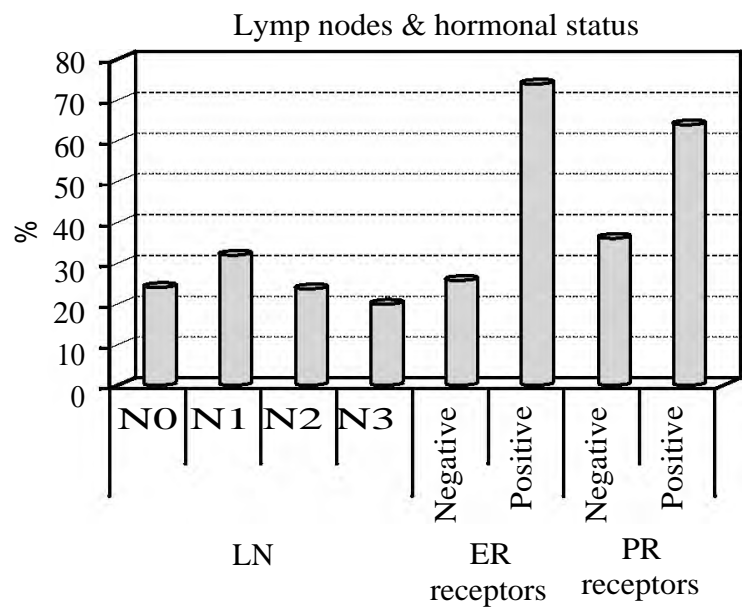

Fig. (4): Lymph nodes and hormonal status.

There were two types of surgery used depending on indications; MRM in 23 patients (46\%) when there were contraindications of CBS or patients preferred radical surgery and CBS in 27 patients (54\%) when indicated. Outcome of surgery; flap necrosis was reported in 2 patients $(4 \%)$, seroma in 3 patients $(6 \%)$ but infection only in one patient $(2 \%)$. Recurrence was observed in ten patients $(20 \%)$. Three patients $(6 \%)$ died during their follow up due to distant metastasis. Table (4), Fig. (5).

Table (4): Types and outcome of surgery \& prognosis of patients.

\begin{tabular}{lcc}
\hline Variable & No. $(\mathrm{N}=50)$ & $(100 \%)$ \\
\hline Type of surgery: & & \\
MRM & 23 & 46.0 \\
CBS & 27 & 54.0 \\
Outcome of surgery: & & \\
$\quad$ Flab necrosis & 2 & 4.0 \\
Seroma & 3 & 6.0 \\
Wound infection & 1 & 2.0 \\
Prognosis of patients: & & \\
Recurrence & 10 & 20 \\
Overall survival & 47 & 94 \\
\hline
\end{tabular}

MRM = Modified Radical Mastectomy.

CBS = Conservative Breast Surgery.

Data are presented as numbers \& percentages are in parenthesis.

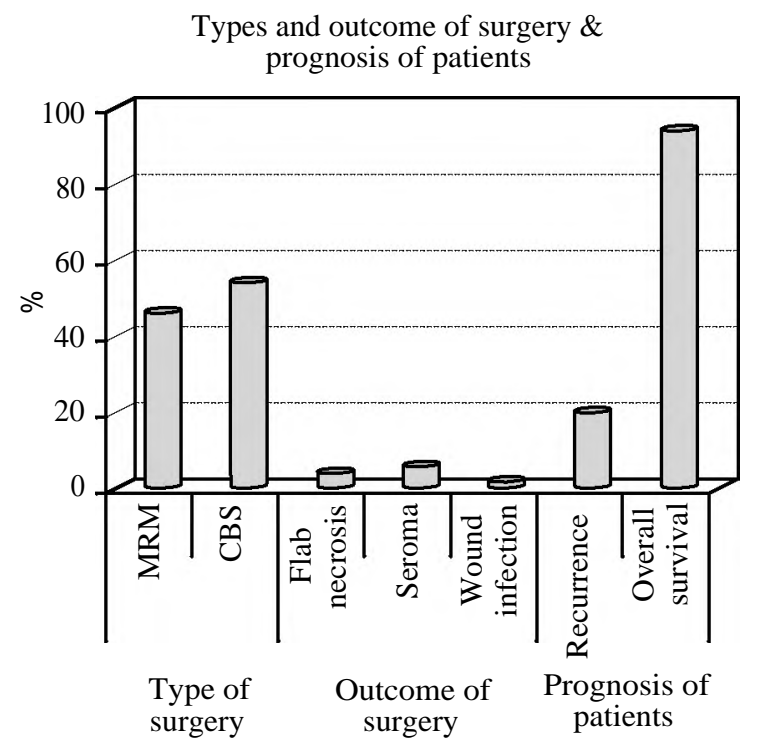

Fig. (5): Types and outcome of surgery.

Aggressive Lymph nodes involvement; N3; was observed in younger patients; $46.6 \pm 11.8$. The size of $\mathrm{N} 3$ was $8.6 \pm 3.83$. There was statistical significance in correlation between nodal status and Size of the tumor; KW test $\& p ; 8.08 \& 0.044$ (S) respectively. Table (5), Fig. (6).

Table (5): Correlation between nodal status and Age and Size of the tumor.

\begin{tabular}{ccccc}
\hline & \multicolumn{2}{c}{ Age (years) } & & \\
\cline { 2 - 3 } Variable & Mean \pm SD & Range & ANOVA & $p$ \\
\hline Nodal status: & & & & \\
$\mathrm{N}_{0}=12$ & $47.6 \pm 8.74$ & $38-65$ & 2.66 & 0.059 (NS) \\
$\mathrm{N} 1=16$ & $53.3 \pm 9.56$ & $38-73$ & & \\
$\mathrm{~N} 2=12$ & $57.2 \pm 11.8$ & $44-84$ & & \\
$\mathrm{~N} 3=10$ & $46.6 \pm 11.8$ & $29-63$ & &
\end{tabular}

Size $(\mathrm{cm})$

KW test $p$

Nodal status:

$\begin{array}{lllll}\mathrm{N}_{0}=12 & 4.51 \pm 3.55 & 0.16-12 & 8.08 & 0.044(\mathrm{~S}) \\ \mathrm{N} 1=16 & 5.20 \pm 2.53 & 1.8-10.5 & & \\ \mathrm{~N} 2=12 & 5.43 \pm 3.53 & 2.1-15.4 & & \\ \mathrm{~N} 3=10 & 8.6 \pm 3.83 & 3.8-16.0 & & \end{array}$

- Data are presented as numbers \& mean \pm SD.

- Percentages \& ranges are in parenthesis using ANOVA \& KW test $\& p$-value.

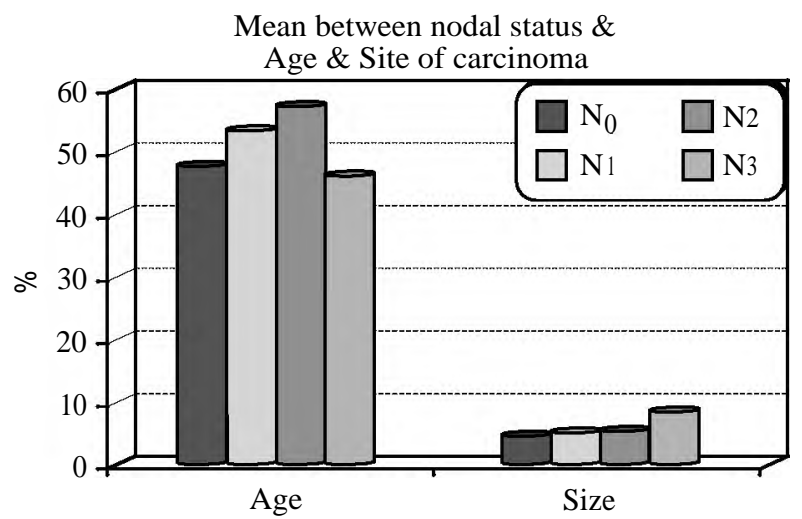

Fig. (6): Correlation between nodal status and Age and Size of the tumor. 
Most of patients with positive progesterone receptors; 30/50 patients (93.8\%); had carcinoma in upper outer quadrant and there was statistical significance in correlation between PR receptors and Site of the tumor; FET \& $p ; 7.05 \& 0.041$ (S) respectively. Table (6), Fig. (7).

Table (6): Correlation between PR receptors and site of carcinoma.

\begin{tabular}{lllllll}
\hline & \multicolumn{4}{c}{ PR receptors } & & \\
\cline { 2 - 4 } Variable & $\begin{array}{c}\text { Negative } \\
(\mathrm{N}=18)\end{array}$ & $\begin{array}{c}\text { Positive } \\
(\mathrm{N}=32)\end{array}$ & $\begin{array}{c}\text { Total } \\
\text { N }(\%)\end{array}$ & $\begin{array}{c}\text { FET \& } \\
\mathrm{P}\end{array}$ \\
\cline { 2 - 4 } & $\mathrm{N}$ & $\%$ & $\mathrm{~N}$ & $\%$ & & \\
\hline $\begin{array}{l}\text { Site of } \\
\text { carcinoma: }\end{array}$ & & & & & & \\
$\quad$ UOQ & 13 & 72.2 & 30 & 93.8 & $43(86 \%)$ & $7.05 \&$ \\
LOQ & 2 & 11.1 & 1 & 3.1 & $3(6 \%)$ & $0.041(\mathrm{~S})$ \\
LIQ & 3 & 16.7 & 0 & 00 & $3(6 \%)$ & \\
$\quad$ UIQ & 0 & 00 & 1 & 3.1 & $1(2 \%)$ & \\
\hline Total & 18 & 100 & 32 & 100 & $50(100 \%)$ & \\
\hline
\end{tabular}

- Data are presented as numbers; percentages \& ranges are in parenthesis using FET \& $p$-value.

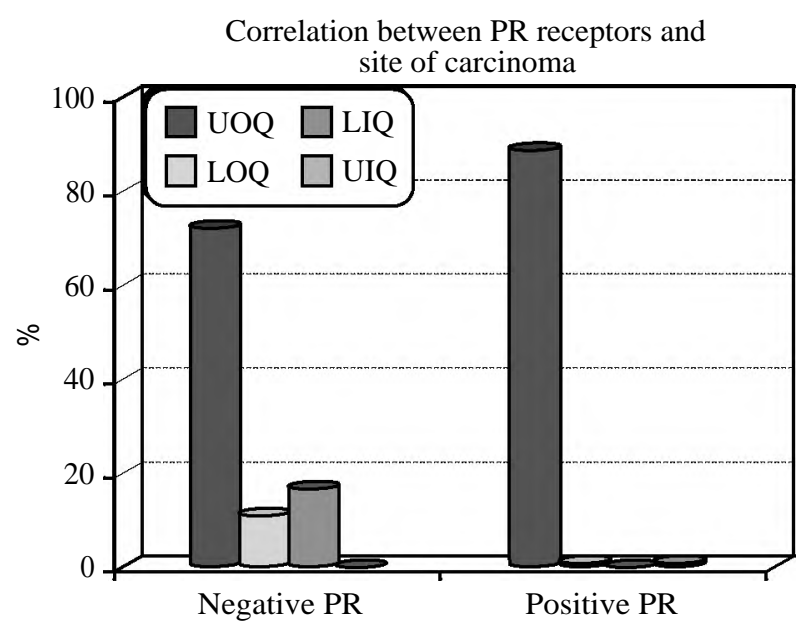

Fig. (7): Correlation between PR receptors and site of carcinoma.

\section{Discussion}

Breast cancer (BC) is the most common health problem in women that its incidence is increasing rapidly. It is the fifth cause of death and third burden of disease among women malignant disease [10].

There were few preceding literature and research work that addressed the tumor expression and the clinical stage. This study was designed to those females with HER2 positive patients with breast cancer to study relationship between HER2 and prognostic factors of 50 cases of breast cancer during four years. Female patients with metastasis were excluded to avoid the effect of metastatic tumor load on the gene expression [11-13].
The rationale of this study was to discuss the clinico-pathological prognostic factors in HER2/neu positive breast cancer for selection of adjuvant regimen based on the clinico-pathological stage only. So, cost-effectively, patient could be saved enormous amount of budget needed for assessment of gene expression.

In the current study, the demographic features of the studied group showed the following; Age range was 29-84 years old with Mean \pm SD was $51.6 \pm 10.9$; All patients were fit for general anesthesia depending on American Society of Anesthesiologists; ASAI and ASAII. Site of the tumor was common in UOQ; 43 patients (86\%). The range of tumor size was $(0.2-16.0 \mathrm{~cm})$ with Mean $\pm \mathrm{SD}$; $5.8 \pm 3.5$. These demographic features were comparable to "Amirifard et al." who mentioned in his study; The mean age for the patients at diagnosis was $46.02 \pm 8.04$ years, $100 \%$ female and The most frequency tumor location was belonging to upper outer of breast and the less frequency was belonging to inner and axillary tail of breast [14]. Also were line with "Abdollahi et al." who reported in his study; the mean age of the patients was $54.8 \pm 11.4$ years $[15]$.

In tumor histopathology; most of tumors were invasive in 47 patients $(94 \%)$ and others were insitu. Recorded types were ductal carcinoma in 41 patients (82\%) and others were lobular carcinoma, ductal carcinoma insitu, mucinous carcinoma and undifferentiated carcinoma. Distribution of these types was less than observed by "Chuangsuwanich et al."; Of 100 BC cases, 89 cases had invasive ductal carcinomas, 4 cases had invasive lobular carcinomas and 7 had other types [16]. But this distribution was slightly more than mentioned by "Amirifard et al."; Of 130 cases, 104 had invasive ductal carcinomas, 16 had invasive lobular carcinomas and 10 had other types [14]

As regard to lymph nodes and hormonal status; positive lymph nodes were nearly equally distributed. It should be noted that lymph node metastases are the most significant prognostic factors in breast carcinoma [17]; these lymph nodes involvement were comparable to "Amirifard et al." who noticed in his study; NO in 45 patients $(34.6 \%) \mathrm{N} 1$ in 51 patients $(39.2 \%) \mathrm{N} 2$ in 25 patients $(19.2 \%) \mathrm{N} 3$ in 9 patients (6.9\%) [11]. But hormonal status; patients with positive ER \& PR receptors were $37 \& 32$ patients $(74.0 \% \& 64.0 \%)$ respectively. This result was near similar to "Abdollahi et al." who mentioned in his study; Estrogen and progesterone receptor were positive in $(70.6 \% \& 66.6 \%)$ of patients respectively [15]. But this result was more 
than reported by "Amirifard et al."; ER \& PR receptors were positive in 13,15 patients $(19.6 \%$, $22.7 \%$ ) respectively [14]

By reviewing types of surgery used; There were two types depending on indications; MRM in 23 patients $(46 \%)$ when there were contraindications of CBS or patients preferred radical surgery and CBS in 27 patients (54\%) when indicated. This was comparable to "Abdollahi et al." who reported in his study; type of surgery used was Mastectomy in $(66 \%)$ and Quadrectomy in (34\%) of his patients [15].

Current study showed that 1-year to 2-years rate of survival in studied patients was 47 patients (94\%). This result was near similar to "Abdollahi et al." who reported in his study; According to results of Kaplan-Meier test, 1-, 3-, 5- and 7-year rates of survival without recurrence were $96.4 \%$, $78.4 \%, 66.3 \%$, and $54.8 \%$, respectively $[15,18]$.

Recurrence of disease is one of the major problems in patients with breast cancer during the first 2 years after diagnosis. Now, considering advanced surgical techniques and complementary therapies, the rate of breast cancer recurrence has decreased. Recurrence rate was observed in ten patients $(20 \%)$. Three patients $(6 \%)$ died during their follow-up due to distant metastasis; patient with anaplastic carcinoma died after 4 months follow-up, patient wit lobular carcinoma died after 14 months followup and last patient with ductal carcinoma died after 22 months follow-up. Reported outcome of surgery in the current study was; flap necrosis in 2 patients (4\%), seroma in 3 patients $(6 \%)$ but infection only in one patient (2\%). The present study recurrence rate was near similar to "Abdollahi et al." report; recurrence either local or distant was (22.9\%) of his patients $[\mathbf{1 5 , 1 9 ]}$.

Kheradmand et al., [20] showed no significant correlation between age, tumor site and size, nodal status, type and histology of tumor in 114 patients with breast cancer underwent mastectomy. In agreement with Kheradmand et al., we found no significant correlation between age, ER receptors and other prognostic factors. However, in contrast to their results we found a significant correlation between nodal status, histopathology, site and tumor size, type of carcinoma and size of the tumor and PR receptors and site of carcinoma. Also there was no statistical significance in correlation between outcome and type of surgery. The differences between these two studies may be explained by difference in sample volume.
Conclusion: Prognostic factors in HER-2 positive patients with breast cancer play important roles and it is considered an indicator of recurrence and the predictor of overall survival. The most significant prognostic is axillary lymph nodes involvement.

\section{References}

1- VON SMITTEN K.: Surgical management of breast cancer in the future. Acta. Oncol., 39 (3): 437-9, 2000

2- BLICHERT-TOFT M.: Axillary surgery in breast cancer management-background, incidence and extent of nodal spread, extent of surgery and accurate axillary staging, surgical procedures. Acta. Oncol., 39 (3): 269-75, 2010.

3- JACOBSON J., DANFORTH D. and COWAN K.: Tenyear results of a comparison of conservation with mastectomy in the treatment of stage I and II breast cancer. $\mathrm{N}$. Engl. J. Med. Apr., 6; 332 (14): 907-11, 1995.

4- LOHRISCH C. and PICCART M.: An overview of HER2. Semin Oncol. Dec., 28 (6 Suppl 18): 3-11, 2001.

5- LICHTENSTEIN P., HOLM N. and VERKASALO P.: Environmental and heritable factors in the causation of cancer analyses of cohorts of twins from Sweden, Denmark, and Finland. N. Engl. J. Med. Jul., 13; 343 (2): 78$85,2000$.

6- GOLDHIRSCH A., GLICK J. and GELBER R.: Meeting highlights: International Consensus Panel on the Treatment of Primary Breast Cancer. Seventh International Conference on Adjuvant Therapy of Primary Breast Cancer. J. Clin. Oncol. Sep., 15; 19 (18): 3817-27, 2011.

7- DISIS M. and SCHIFFMAN K.: Cancer vaccines targeting the HER2/neu oncogenic protein. Semin Oncol. Dec., 28 (6 Suppl 18): 12-20, 2011.

8- HAIT W.: The prognostic and predictive values of ECDHER-2. Clin. Cancer Res. Sep., 7 (9): 2601-4, 2011.

9- YAMAUCHI H., STEARNS V. and HAYES D.: When is a tumor marker ready for prime time? A case study of cerbB-2 as a predictive factor in breast cancer. J. Clin. Oncol. Apr., 15; 19 (8): 2334-56, 2001.

10- MOHAMMADI S., SULAIMAN S. and KOON P.: Association of nutritional status with quality of life in breast cancer survivors. Asian Pac. J. Cancer Prev., 14: 774955, 2013.

11- MOLINA M., CODONY-SERVAT J., ALBANELL J., ROJO F., ARRIBAS J. and BASELGA J.: (Herceptin), a humanized anti-HER-2/neu receptor monoclonal antibody inhibits basal and activated HER2 ectodomain cleavage in breast cancer cells. Cancer Res., 61: 4744-4749, 2001.

12- SLAMON D.J., LEYLAND-JONES B. and SHAK S.: Use of chemotherapy plus a monoclonal antibody against HER2 for metastatic breast cancer that overexpresses HER2. N. Engl. J. Med., 344: 783-792, 2001.

13- HAJIHOSSEINI M., FARADMAL J. and SADIGHIPASHAKI A.: Survival Analysis of Breast cancer patients after surgery with an intermediate event: Application of illness-death model. Iran J. Public Health, 44: 1677-84, 2015. 
14- AMIRIFARD N., SADEGHI E., PAYANDEH M., MOHEBBI H., SADEGHI M. and CHOUBSAZ M.: Relationship between HER2 Proto-oncogene Status and Prognostic Factors of Breast Cancer in the West of Iran; Asian Pac. J. Cancer Prev., 17 (1): 295-298, 2016.

15- ABDOLLAHI A., ZADEH H., AKBARI M., TAHMASBI S., TALEI A. and HASSANZADEH J.: Investigation of Prognostic Factors and Survival without Recurrence in Patients with Breast Cancer. Adv. Biomed. Res., 6: 42, 2017.

16- CHUANGSUWANICH T., PONGPRUTTIPAN T. and O-CHAROENRAT P.: Clinicopathologic features of breast carcinomas classified by biomarkers and correlation with microvessel density and VEGF expression: A study from Thailand. Asian Pac. J. Cancer Prev., 15: 1187-92, 2014.

17- OLSZEWSKI W., SZUMERA-CIECKIEWICZ A. and
PIECHOCKI J.: The characteristics of sentinel lymph node metastasis in predicting axillary lymph node status in patients with breast carcinoma. Pol. J. Pathol., 60: 13843, 2009.

18- BREWSTER A.M., HORTOBAGYI G.N., BROGLIO K.R., KAU S.W., SANTA-MARIA C.A. and ARUN B.S.: Residual risk of breast cancer recurrence 5 years after adjuvant therapy. J. Natl. Cancer Inst., 100: 1179-83, 2008 .

19- NOJOUMI M., MIRFAKHRAEI R. and HOSSEINI N.: Relationship between hormonal factors and breast cancer. Hakim J., 7: 19-25, 2004.

20- KHERADMAND A., RANJBARNOVIN N. and KHAZAEIPOUR Z.: Postmastectomy locoregional recurrence and recurrence-free survival in breast cancer patients. World J. Surg. Oncol., 8: 30, 2010.

\section{مستقبلات الهرمونات هير r الايجابية}

الهدف من الدراسـة: الأساس المنطقى لهذه الدراسة هو مناقشة العوامل النذير المرضية السريرية في HER2 / neu سرطان الثىى الإيجمابمى.

المرضى والطرق: أجريت هذه الدراسة الحالية على •0 مريضاً تم تشخيصهم بسرطان الثدى. خضع المرضى فى هذه الداسة إما

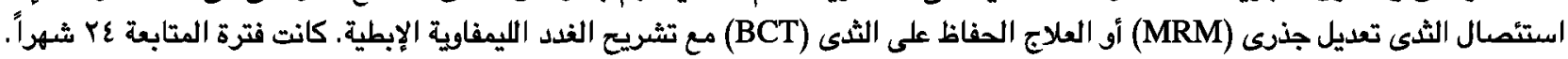

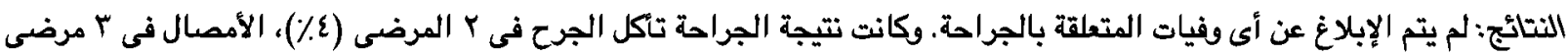

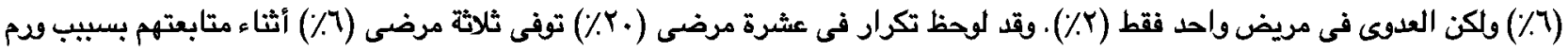

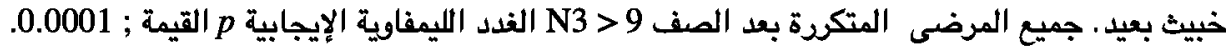

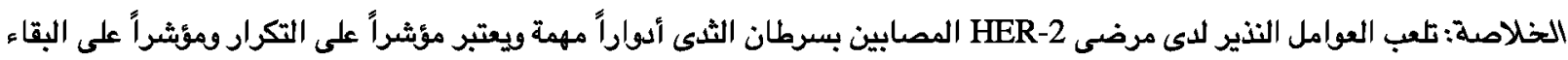

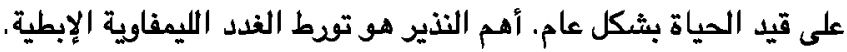

